\title{
PERFIL SOCIOECONÔMICO DE PRODUTORES DE LEITE DA REGIÃO SUDOESTE DO PARANÁ: UM ESTUDO A PARTIR DE DIFERENTES NÍVEIS DE PRODUTIVIDADE ${ }^{1}$
}

\author{
José Luiz Parré2 \\ Sandra Mara Schiavi Bánkuti ${ }^{3}$ \\ Nelito Antonio Zanmaria ${ }^{4}$
}

\begin{abstract}
Resumo: O presente trabalho busca caracterizar produtores de leite da região Sudoeste do Paraná, identificando aspectos técnicos, tecnológicos, gerenciais, econômicos e sociais que diferenciam os produtores com níveis de produtividade distintos. Para tanto, foram aplicados 202 questionários e, com auxílio da metodologia de análise de clusters, foram encontrados três grupos com características distintas em termos de produtividade. Pôde-se constatar que os produtores da região em estudo apresentam, em média, indicadores superiores aos observados para o Estado, o que indica melhor organização do sistema leiteiro na região Sudoeste. Foram identificadas algumas diferenças relevantes entre produtores de diferentes níveis de produtividade. Os produtores com baixa produtividade do rebanho têm como principal ocupação o trabalho rural, produzem menor volume de leite e estão há mais tempo na atividade leiteira, o que pode indicar dependência de trajetória. Além disso, maior proporção de produtores desse grupo não tem o leite como principal atividade e apresentam limitações para atuação agropecuária, seja por possuírem menor tamanho de área, seja por características da propriedade, o que compromete o desempenho na atividade. Outras limitações dizem respeito ao nível tecnológico, ao uso de mecanismos de gestão agropecuária, ao acesso a crédito, assistência e capacitação e à realização de investimentos na atividade leiteira.
\end{abstract}

Palavras-chaves: Produtividade leiteira; Região Sudoeste do Paraná; SAG do leite

Recebido em: 23/08/2011. Aceito em: 28/10/2011.

2 Professor Associado, Departamento de Economia da Universidade Estadual de Maringá - PR, bolsista produtividade CNPq. E-mail: jlparre@uem.br

3 Professora Adjunta, Departamento de Administração da Universidade Estadual de Maringá - PR, E-mail: smsbankuti@uem.br

4 Mestre em Teoria econômica - UEM. E-mail: nelitozanmaria@yahoo.com.br 


\begin{abstract}
The aim of this work is to characterize milk producers in Southwestern Paraná. It has been considered technical, technological, managerial, economic and social aspects. 202 producers have been interviewed, grouped into three distinct clusters, according to productivity levels. As results, milk producers in the region presented, on average, superior indicators when compared to data in Paraná, ratifying better organization and productive system in the region. Relevant differences among producers with different productivity levels could be pointed out. Low-productivity producers, in general, are more engaged in rural work, produce low volume of milk and work in milk activity for longer time, which can indicate path dependency. Besides that, higher percentage of producers in that group doesn't have milk as main activity and present limitations related to either farm size or farm characteristics. Other limitations are related to technological level, management systems, access to credit, technical and managerial assistance, training and investments in milk activity.
\end{abstract}

Keywords: Milk chain, milk productivity, Southwestern Paraná.

\title{
1. Introdução
}

O Sistema Agroindustrial (SAG) do leite vem sofrendo mudanças rápidas e expressivas nas duas últimas décadas (MARTINS, 2005; TETZNER et al., 2005). Significativas alterações vêm ocorrendo no perfil das agroindústrias laticinistas, na geografia da produção primária e no destino dos produtos lácteos (BÁNKUTI, 2007). Na década de 90, com a implantação da abertura comercial e da desregulamentação de mercados, especialmente com o fim do controle estatal de preços ao produtor e ao consumidor, houve um desencadeamento de mudanças no SAG do leite, levando a que investimentos passassem a ser bem mais atrativos, bem como a um processo de reorganização setorial (DÜRR, 2004).

Tais mudanças implicaram alterações na dinâmica competitiva desse SAG no país, inclusive em bacias leiteiras tradicionais, entre as quais se encontra o estado do Paraná (JANK, FARINA e GALAN, 1999). Neste estado, encontram-se três principais bacias de na produção de leite: Centro-Oriental, Oeste e Sudoeste. Estas três bacias envolvem 95 municípios, concentram $48,5 \%$ dos produtores e são responsáveis por $53 \%$ da produção estadual de leite (IPARDES, 2008). A expansão da 
produção leiteira no Paraná foi mais intensa nas regiões Oeste e Sudoeste do Estado, com forte crescimento do rebanho e dos níveis de produtividade.

Das três principais bacias leiteiras do estado, a região Sudoeste se encontra em processo de consolidação, com crescimento nos níveis de produção e produtividade e avanços em termos tecnológicos. Enquanto a produtividade média do rebanho leiteiro no Paraná cresceu, entre 1997 e 2006, 29\%, na região Sudoeste esse aumento foi de 74\% (IPARDES, 2008).

Além disso, destaca-se ainda nessa região o forte vínculo da produção leiteira com a agricultura familiar, indicando a relevância social dessa atividade. A média de produtividade das vacas leiteiras da região, em 2006/2007, foi de 9,4 litros/vaca/dia, bem acima da média nacional no período (IPARDES, 2010). ${ }^{5}$ Segundo Parré et al. (2010), observam-se avanços na pecuária leiteira do Sudoeste do Paraná, principalmente em se tratando de melhoria de tecnologias de produção, associadas a fatores técnicos e organizacionais, tais como uso de rebanho e mão de obra especializados e estrutura cooperativista atuante.

As recentes alterações institucionais, organizacionais e tecnológicas têm propiciado novo contexto competitivo nesse SAG, induzindo novas dinâmicas ao longo da cadeia de produção. Ganhos de competitividade do SAG dependem da coordenação e do desempenho dos agentes da cadeia. Considerando a produtividade do rebanho importante fator de desempenho na produção rural, bem como a visão de competitividade sistêmica, entende-se que melhorias nesse índice podem auxiliar no melhor desempenho da cadeia como um todo, mostrando, portanto, ser um ponto relevante de estudo.

Destaca-se que o Sudoeste Paranaense está cercado por três regiões com desempenho considerável na atividade leiteira: o Oeste Catarinense, o Oeste Paranaense e o Centro-Sul Paranaense. Considerando os efeitos de transbordamento e as possibilidades de sinergia, pode-se esperar que o bom desempenho na produção leiteira nessa região sofra influências benéficas decorrentes de sua localização geográfica. 
Dados a dinâmica do SAG do leite no Paraná e os avanços da atividade na região Sudoeste, o presente trabalho busca identificar o perfil socioeconômico de produtores rurais de leite no Sudoeste Paranaense, segundo diferentes níveis de produtividade. Busca-se, especificamente, identificar aspectos técnicos, tecnológicos, gerenciais, econômicos e sociais que diferenciam os produtores com níveis de produtividade distintos.

\section{Material e métodos}

Para a realização deste trabalho, foram utilizados dados primários provenientes da aplicação de questionários estruturados junto a 202 produtores rurais da região Sudoeste do Paraná, no início do ano de 2010. O questionário englobou questões relativas à atividade agropecuária e leiteira nos anos de 2008 e 2009, das quais foram utilizadas informações acerca do último ano, especificamente no que concerne aos seguintes aspectos: características do produtor rural, características do estabelecimento rural, características do trabalho, comercialização da produção leiteira, variáveis técnicas como infraestrutura e custos de produção e participação em organizações coletivas. A amostragem foi aleatória e os questionários foram aplicados individualmente ou em ocasiões coletivas, tais como reuniões de produtores rurais na região em estudo. Ressalta-se que informações sobre a atividade leiteira no Paraná, disponíveis em IPARDES (2008), foram utilizadas como referência na análise dos resultados para contextualização dos dados primários obtidos com a pesquisa. ${ }^{6}$

A análise de clusters permite que sejam obtidos grupos com características semelhantes entre si e distintas dos outros grupos, através da escolha de uma ou mais variáveis (KAUFMAN, ROUSSEAU, 1990; DURAN, ODELL, 1974). Dentro da análise de cluster, existem diferentes métodos que podem ser utilizados. Um dos métodos é o

O questionário completo está apresentado em Zanmaria (2010). 
hierárquico, que pode ser ascendente (o algoritmo de cálculo inicia com tantos grupos quantos elementos e finaliza ao se reagrupar todo o conjunto) e o descendente (o conjunto inicial de elementos vai sendo subdividido em agrupamentos cada vez menores). Outro procedimento é o método não hierárquico, pois há uma interação entre K grupos, utilizando alguns critérios que fazem com que se minimize a variância intergrupos. O método utilizado neste trabalho é o não hierárquico $K$-means, pois apresenta um bom desempenho quando se trata de um pequeno número de grupos em relação ao número de elementos utilizados (LEBART et al., 1986).

Uma das regras que pode ser utilizada para definir o número de clusters é quando a distância entre eles aumenta significativamente. A distância pode ser encontrada pela fórmula:

$$
\mathrm{D}_{\mathrm{i}, \mathrm{j}}^{2}=\sum_{\mathrm{k}=1}^{\mathrm{p}}\left(\mathrm{x}_{\mathrm{i}, \mathrm{k}}-\mathrm{x}_{\mathrm{j}, \mathrm{k}}\right)^{2}
$$

Em que:

$$
\mathrm{D}_{\mathrm{i}, \mathrm{j}}^{2}=\text { Quadrado da distância entre os pares de variáveis i e j; }
$$

$\mathrm{X}_{\mathrm{i}, \mathrm{k}}=$ valor da k-ésima variável para o i-ésimo par de variáveis;

$\mathrm{X}_{\mathrm{j}, \mathrm{k}}=$ valor da k-ésima variável para o j-ésimo par de variáveis; e $\mathrm{p}=$ número de variáveis.

A qualidade da solução foi avaliada pela análise de variância (teste F). A distância centroide deve ser pequena para unir dois clusters, caso contrário os grupos unidos são dissimilares. Em suma, pode-se definir a seguinte regra: quando ocorrer um salto no valor destas estatísticas, o número de cluster é definido a partir deste valor. 
A partir da utilização do software SPSS, versão 9,5, foi analisado um elemento do questionário, obtendo um resultado coeso, passível de análise. O elemento escolhido para análise foi a produtividade do rebanho leiteiro para o ano de 2009 (QPROD.09). A produtividade foi calculada a partir das respostas às questões "volume de leite produzido em 2009" e "número de vacas em lactação no ano de 2009", resultando na variável "litros de leite/vacas em lactação/dia" (1/vl/dia). Considerando-se na análise um nível de significância de 1\% (um por cento), chegou-se à análise de variância do Quadro 1.

\begin{tabular}{|l|c|c|c|c|c|c|}
\hline & \multicolumn{2}{|c|}{ Cluster } & \multicolumn{2}{c|}{ Erro } & & $\cdot$ \\
\hline \multirow{2}{*}{ Variável } & Quadrado Médio & G. L. & $\begin{array}{c}\text { Quadrado } \\
\text { Médio }\end{array}$ & G. L. & F & $\begin{array}{c}\text { Nível } \\
\text { de Sig. }\end{array}$ \\
\hline QPROD.09 & 1934,396 & 2 & 4,239 & 199 & 456,299 &, 000 \\
\hline
\end{tabular}

Quadro 1 - ANOVA - Análise de variância do cluster.

Fonte: Resultados obtidos a partir dos dados da pesquisa

Os resultados mostram que foram obtidos três clusters a partir das informações sobre a produtividade contida nos questionários, ou seja, foi possível obter três grupos diferenciados de produtores de leite para a Região Sudoeste, denominados de "alta produtividade", "média produtividade" e "baixa produtividade". Esses grupos de produtores foram comparados, utilizando-se para isso respostas a outras questões do questionário. Dessa forma, foi possível fazer uma diferenciação de aspectos como grau de escolaridade, tempo na atividade leiteira, renda proveniente da atividade leiteira, especialização do rebanho, acesso à capacitação e à assistência técnica, entre outros, para os grupos encontrados. 


\section{Resultados e discussão}

Conforme mencionado, os 202 produtores entrevistados na região Sudoeste do Paraná foram agrupados em clusters segundo níveis de produtividade do rebanho leiteiro. A discussão dos resultados, portanto, seguirá tal grupamento.

De uma maneira geral, no que concerne à produtividade do rebanho leiteiro, os entrevistados da região Sudoeste apresentaram índice médio de 14,5 1/vl/dia, superior ao observado no estado do Paraná, de 10,9 1/vl/ dia (IPARDES, 2008). Pela Tabela 01, observa-se que o cluster 1 possui 90 produtores, o cluster 2 ficou com 26 produtores e o cluster 3 com 86 produtores, perfazendo um total de 202 produtores estudados. Para o cluster 1, a produtividade média é de 12,09 1/vl/dia, sendo nominado cluster de média produtividade. O cluster 2 , com produtividade média de 19,48 1/vl/dia, é o cluster de alta produtividade e, por conseguinte, o cluster 3 ficou denominado como de baixa produtividade por apresentar uma produtividade média de $6,261 / \mathrm{vl} / \mathrm{dia}$.

Características como idade, grau de escolaridade do produtor rural e tempo inserido na atividade leiteira se mostram relevantes à medida que indicam a capacidade do produtor em se adequar à dinâmica recente do SAG do leite, considerando, por exemplo, a dependência de trajetória e a resistência a inovações.

Pela Tabela 01, podem-se identificar semelhanças entre os produtores de cada cluster, e embora haja diferença entre os níveis médios de produtividade do rebanho leiteiro, os grupos se assemelham no que concerne ao tamanho médio da propriedade, percentual de produtores com área própria e idade média do produtor. A condição de proprietário da terra, que compreende a grande maioria nos três clusters, é relevante por indicar o comprometimento do produtor com a atividade agropecuária e a possibilidade de realização de melhorias tais como benfeitorias e infraestrutura, investimentos, que podem ser tornar inexequíveis em propriedade alheia. Além disso, a condição de proprietário também pode 
facilitar investimentos pela possibilidade de captação de crédito rural usando a terra como garantia. Assim, os produtores entrevistados dos três clusters, em sua maioria, não apresentaram tais tipos de restrições.

Tabela 01 - Caracterização geral dos produtores

\begin{tabular}{lccc}
\hline & Cluster 1 & Cluster 2 & Cluster 3 \\
\hline Nível de produtividade & Média & Alta & Baixa \\
Produtores & 90 & 26 & 86 \\
Produtividade média (1/vl/dia) & 12,1 & 19,5 & 6,3 \\
$\quad$ Mínimo & 9,2 & 16,0 & 3,0 \\
$\quad$ Máximo & 15,7 & 29,3 & 9,1 \\
$\quad$ Desvio Padrão & 1,7 & 3,6 & 2,8 \\
Tamanho (hectares) & 24,2 & 24,4 & 25,2 \\
Área própria & $92,2 \%$ & $92,3 \%$ & $89,3 \%$ \\
Idade do produtor (anos) & 46,1 & 46,3 & 45,1 \\
\hline
\end{tabular}

Fonte: Dados da pesquisa.

Os estabelecimentos rurais para os três clusters têm em média 24,7 hectares, o que assinala pequena propriedade, característica da região em estudo (IPARDES, 2008). De fato, ao averiguar os estratos de tamanho da área para os diferentes clusters, observa-se, pela Tabela 02, que parte considerável dos produtores se estabelece em minifúndios, menos de um módulo fiscal (48\% no grupo de média produtividade, $46 \%$ no de alta produtividade e $53 \%$ no de baixa), indicando limitações de tamanho de área. Isso poderia comprometer a eficiência produtiva por falta de área para pastagens e restrições para captação de crédito, por exemplo, ou induzir o uso de sistemas intensivos de produção 7 . Ressaltamse a ausência de grandes estabelecimentos e a pequena proporção de médias propriedades na amostra.

De acordo com o Estatuto da Terra (Lei n. 4504), os minifúndios são entendidos como áreas economicamente inadequadas, com possibilidades inferiores às da agricultura familiar (BRASIL, 1964). Entende-se que, apesar dos avanços tecnológicos na agricultura, que viabilizam a pecuária intensiva, restrições de tamanho de terra, no mínimo, limitam as ações dos produtores. Áreas pequenas podem, por exemplo, impedir alcance de escala ou direcionar a determinados sistemas de produção. 
Tabela 02 - Estratificação, segundo tamanho do estabelecimento rural (hectares)*

\begin{tabular}{lccc|ccccccc}
\hline & \multicolumn{3}{c}{ Média } & \multicolumn{3}{c}{ Alta } & \multicolumn{3}{c}{ Baixa } \\
Tamanho & Mini. & Peq. & Méd & Mini. & Peq. & Méd. & Mini. & Peq. & Méd. \\
\hline Frequência & 44 & 46 & 0 & 12 & 13 & 1 & 46 & 37 & 3 \\
Média & 12,7 & 35,2 & 0 & 14,3 & 28,2 & 97 & 12,5 & 31,5 & 143,3 \\
Desvio Padrão & 3,7 & 15,4 & 0 & 4,2 & 9,2 & 0 & 4,1 & 12,7 & 92,9 \\
\hline
\end{tabular}

* Considerando a classificação do Estatuto da Terra e o valor de referência de 20 hectares por módulo fiscal para a região em estudo.

Fonte: Dados da pesquisa.

Com relação à idade do produtor, observa-se, na Tabela 01, que os três grupos apresentaram idade média de 45 anos. Ao verificar as faixas etárias, Tabela 03, pode-se destacar que na região Sudoeste observa-se um percentual baixo de produtores com mais de 50 anos de idade, bem como uma concentração maior de produtores na faixa intermediária (de 36 a 50 anos). Considerando dados do Paraná (IPARDES, 2008), que indica que $51 \%$ dos produtores de leite têm mais de 50 anos de idade, pode-se afirmar que a região em estudo se caracteriza por produtores mais jovens.

Tabela 03 - Faixa etária do produtor rural

\begin{tabular}{l|c|c|c|c|c|c}
\hline \multirow{2}{*}{ Faixa etária } & \multicolumn{2}{|c|}{ Média } & \multicolumn{2}{c|}{ Alta } & \multicolumn{2}{c}{ Baixa } \\
\cline { 2 - 7 } & $\mathbf{N}$ & $\%$ & N & $\%$ & N & $\%$ \\
\hline Até 35 anos & 6 & $7 \%$ & 0 & $0 \%$ & 3 & $3 \%$ \\
De 36 a 50 anos & 64 & $71 \%$ & 22 & $85 \%$ & 66 & $77 \%$ \\
Mais de 50 anos & 20 & $22 \%$ & 4 & $15 \%$ & 17 & $20 \%$ \\
\hline Total & $\mathbf{9 0}$ & $\mathbf{1 0 0} \%$ & $\mathbf{2 6}$ & $\mathbf{1 0 0} \%$ & $\mathbf{8 6}$ & $\mathbf{1 0 0} \%$ \\
\hline
\end{tabular}

Fonte: Dados da pesquisa. 
No que concerne à escolaridade, os dados da Tabela 04 deixam claro que os três grupos analisados também apresentam semelhanças, sendo que a maior parte dos produtores completou, pelo menos, o ensino fundamental. Comparando com dados do Estado, observa-se maior grau de instrução na região Sudoeste: mais de $70 \%$ dos produtores de leite paranaenses não completaram nem mesmo o ensino fundamental (IPARDES, 2008).

Tabela 04 - Grau de escolaridade do chefe da família

\begin{tabular}{lcc|cc|cc}
\hline \multicolumn{1}{c}{ Escolaridade } & \multicolumn{2}{c|}{ Média } & \multicolumn{2}{c|}{ Alta } & \multicolumn{2}{c}{ Baixa } \\
& $\mathbf{N}$ & $\mathbf{\%}$ & $\mathbf{N}$ & $\mathbf{\%}$ & $\mathbf{N}$ & $\mathbf{\%}$ \\
\hline Lê/escreve, nunca foi à escola & 1 & $1 \%$ & 0 & $0 \%$ & 1 & $1 \%$ \\
Já frequentou a escola & 42 & $47 \%$ & 12 & $46 \%$ & 39 & $45 \%$ \\
Ensino fundamental & 26 & $29 \%$ & 7 & $27 \%$ & 26 & $30 \%$ \\
Ensino médio & 15 & $17 \%$ & 7 & $27 \%$ & 17 & $20 \%$ \\
Ensino superior & 6 & $7 \%$ & 0 & $0 \%$ & 3 & $3 \%$ \\
\hline Total & $\mathbf{9 0}$ & $\mathbf{1 0 0} \%$ & $\mathbf{2 6}$ & $\mathbf{1 0 0} \%$ & $\mathbf{8 6}$ & $\mathbf{1 0 0} \%$ \\
\hline
\end{tabular}

Fonte: Dados da pesquisa.

A principal ocupação do produtor rural também é relevante para compreender seu comprometimento e dependência com relação à agropecuária. Observa-se, pela Tabela 05, que o grupo de produtores com alta produtividade inclui maior proporção de produtores que não dependem do trabalho na propriedade rural; enquanto para os grupos de baixa e média produtividade, $95 \%$ e $90 \%$ dos entrevistados, respectivamente, têm o trabalho rural na propriedade como principal ocupação; e para o grupo de alta produtividade, esse número é de $77 \%$. Percebe-se que parcela considerável dos produtores desse grupo $(20 \%)$ tem como principal ocupação atividades não agropecuárias. 
Tabela 05 - Principal ocupação do chefe da família

\begin{tabular}{l|ccc|c|c|c|c}
\hline \multirow{2}{*}{ Tipo de mão de obra } & \multicolumn{2}{|c|}{ Média* } & \multicolumn{2}{c|}{ Alta } & \multicolumn{2}{c}{ Baixa } \\
\cline { 2 - 7 } & $\mathbf{N}$ & $\%$ & $\mathbf{N}$ & $\%$ & $\mathbf{N}$ & $\%$ \\
\hline Familiar & 76 & $88 \%$ & 25 & $96 \%$ & 82 & $95 \%$ \\
Contratada & 7 & $8 \%$ & 1 & $4 \%$ & 4 & $5 \%$ \\
Familiar e contratada & 3 & $3 \%$ & 0 & $0 \%$ & 0 & $0 \%$ \\
\hline Total & 86 & $100 \%$ & 26 & $100 \%$ & 86 & $100 \%$ \\
\hline
\end{tabular}

Fonte: Dados da pesquisa.

Com relação ao trabalho predominante na atividade leiteira, percebe-se que a maioria dos entrevistados dos três clusters utiliza somente mão de obra familiar (Tabela 06), o que reforça o caráter de agricultura familiar na atividade leiteira, especialmente no Paraná e na região Sudoeste. De fato, dados do Censo Agropecuário de 2006 indicam que 84\% dos produtores de leite no Paraná se encontram na definição de agricultor familiar, sendo esse percentual de $91 \%$ para a região Sudoeste (IBGE, 2009). Considerando os dados da pesquisa, pode-se entender que, mesmo nas situações em que o produtor não tenha a atividade rural como principal ocupação, a mão de obra para a produção leiteira é proveniente do trabalho dele ou de outros membros da família.

Tabela 06 - Tipo de mão de obra utilizada na atividade leiteira

\begin{tabular}{l|c|c|c|c|c|c}
\hline \multirow{2}{*}{ Tipo de mão de obra } & \multicolumn{2}{|c|}{ Média* $^{*}$} & \multicolumn{2}{c|}{ Alta } & \multicolumn{2}{c}{ Baixa } \\
\cline { 2 - 7 } & $\mathbf{N}$ & $\%$ & $\mathbf{N}$ & $\%$ & N & $\%$ \\
\hline Familiar & 76 & $88 \%$ & 25 & $96 \%$ & 82 & $95 \%$ \\
Contratada & 7 & $8 \%$ & 1 & $4 \%$ & 4 & $5 \%$ \\
Familiar e contratada & 3 & $3 \%$ & 0 & $0 \%$ & 0 & $0 \%$ \\
\hline Total & 86 & $100 \%$ & 26 & $100 \%$ & 86 & $100 \%$ \\
\hline
\end{tabular}

* Respostas válidas

Fonte: Dados da pesquisa. 
Pelos dados das Tabelas 07 e 08, é perceptível a importância da atividade leiteira para os produtores dos três grupos: a maior parte dos entrevistados (62\% no cluster de média produtividade, $69 \%$ no cluster de alta produtividade e $57 \%$ no de baixa produtividade) indicou a bovinocultura de leite como principal atividade. Entretanto, percebe-se um percentual maior de produtores do grupo de alta produtividade indicando o leite como principal atividade, o que pode estar relacionado ao direcionamento de esforços para essa atividade e, portanto, desempenho melhor.

Tabela 07 - Principal atividade agropecuária

\begin{tabular}{l|cc|cc|cc}
\hline \multirow{2}{*}{ Principal atividade } & \multicolumn{2}{|c|}{ Média } & \multicolumn{2}{c|}{ Alta } & \multicolumn{2}{c}{ Baixa } \\
\cline { 2 - 7 } & $\mathbf{N}$ & $\mathbf{\%}$ & $\mathbf{N}$ & $\mathbf{\%}$ & $\mathbf{N}$ & $\mathbf{\%}$ \\
\hline Bovinocultura de leite & 56 & $62 \%$ & 18 & $69 \%$ & 49 & $57 \%$ \\
Grãos & 22 & $24 \%$ & 6 & $23 \%$ & 20 & $23 \%$ \\
Outras & 12 & $13 \%$ & 2 & $8 \%$ & 17 & $20 \%$ \\
\hline Total & $\mathbf{9 0}$ & $\mathbf{1 0 0} \%$ & $\mathbf{2 6}$ & $\mathbf{1 0 0} \%$ & $\mathbf{8 6}$ & $\mathbf{1 0 0} \%$ \\
\hline
\end{tabular}

Fonte: Dados da pesquisa.

Em termos de composição da renda, maior proporção dos produtores tem na atividade leiteira a principal fonte de renda agropecuária. A renda proveniente da atividade leiteira corresponde a mais da metade da renda agropecuária para $84 \%$ dos entrevistados do cluster de média produtividade; $85 \%$, do cluster de alta produtividade; e $90 \%$ dos produtores de baixa produtividade (Tabela 08). Ressalta-se que, para o cluster de alta produtividade, mais de $80 \%$ dos entrevistados indicaram a atividade leiteira como componente de mais de $75 \%$ da renda agropecuária, o que pode indicar maior especialização da produção para este grupo. 
Tabela 08 - Percentual da renda agropecuária proveniente da atividade leiteira

\begin{tabular}{l|c|c|c|c|c|c}
\hline \multirow{2}{*}{ Estratos } & \multicolumn{2}{|c|}{ Média } & \multicolumn{2}{c|}{ Alta } & \multicolumn{2}{c}{ Baixa } \\
\cline { 2 - 7 } & $\mathbf{N}$ & $\%$ & $\mathbf{N}$ & $\%$ & $\mathbf{N}$ & $\%$ \\
\hline Até $25 \%$ & 1 & $1 \%$ & 1 & $4 \%$ & 0 & $0 \%$ \\
De 25\% a 50\% & 13 & $14 \%$ & 3 & $12 \%$ & 9 & $10 \%$ \\
De 50\% a 75\% & 19 & $21 \%$ & 1 & $4 \%$ & 16 & $19 \%$ \\
Mais de 75\% & 57 & $63 \%$ & 21 & $81 \%$ & 61 & $71 \%$ \\
\hline Total & $\mathbf{9 0}$ & $\mathbf{1 0 0} \%$ & $\mathbf{2 6}$ & $\mathbf{1 0 0} \%$ & $\mathbf{8 6}$ & $\mathbf{1 0 0} \%$ \\
\hline
\end{tabular}

Fonte: Dados da pesquisa.

Em termos de volume de leite produzido (Tabela 09), percebe-se uma relação direta dele com a produtividade: os produtores no cluster de alta produtividade também são aqueles que produziram, em média, maior volume de leite em 2009 (121,5 mil litros), enquanto o grupo de baixa produtividade apresentou a média de volume mais baixa.

Tabela 09 - Produção leiteira (litros /ano)

\begin{tabular}{lccc}
\hline & Média & Alta & Baixa \\
\hline Frequência & 90 & 26 & 86 \\
Média & 81.883 & 121.481 & 48.225 \\
Desvio Padrão & 43.265 & 44.955 & 35.146 \\
\hline
\end{tabular}

Fonte: Dados da pesquisa.

Considerando estratificação proposta em IPARDES (2008), a frequência de produtores em cada faixa de volume diário produzido é mostrada na Tabela 10. Os dados deixam clara a concentração de produtores com maior volume de leite no cluster de alta produtividade: quase $80 \%$ dos entrevistados desse grupo produzem diariamente mais de 250 litros de leite, em média. Os outros dois grupos (média e baixa produtividade) concentram produtores no estrato intermediário (de 51 a 250 litros de leite por dia), ressaltando que apenas o cluster de baixa produtividade contém produtores com pequeno volume (até 50 litros/dia). Considerando os diferenciais de negociação e de pagamento por volume de leite, 
presentes nas relações atuais entre processadores e pecuaristas, podese esperar que produtores do cluster de alta produtividade possam alcançar melhores condições de venda.

Tabela 10 - Produção diária de leite

\begin{tabular}{l|c|c|c|c|c|c}
\hline \multirow{2}{*}{ Estratos } & \multicolumn{2}{|c|}{ Média } & \multicolumn{2}{c|}{ Alta } & \multicolumn{2}{c}{ Baixa } \\
\cline { 2 - 7 } & $\mathbf{N}$ & $\%$ & N & $\%$ & N & $\%$ \\
\hline Até 50 litros & 0 & $0 \%$ & 0 & $0 \%$ & 16 & $18 \%$ \\
De 51 a 250 litros & 64 & $71 \%$ & 6 & $23 \%$ & 60 & $70 \%$ \\
Mais de 250 litros & 26 & $29 \%$ & 20 & $77 \%$ & 10 & $12 \%$ \\
\hline Total & $\mathbf{9 0}$ & $\mathbf{1 0 0} \%$ & $\mathbf{2 6}$ & $\mathbf{1 0 0} \%$ & $\mathbf{8 6}$ & $\mathbf{1 0 0} \%$ \\
\hline
\end{tabular}

Fonte: Dados da pesquisa.

Ao analisar o tempo na atividade leiteira, leva-se em conta a capacidade de adaptações a mudanças recentes no SAG, bem como a inserção do produtor na atividade leiteira dentro do atual contexto competitivo. Ao observar os dados da Tabela 11, pode-se constatar que os produtores do grupo de alta produtividade estão na atividade leiteira, em média, há menos tempo (pouco mais de sete anos), e que parcela considerável deles está na atividade há menos de cinco anos ( $42 \%$ dos entrevistados). Para os outros clusters, o estrato mais representativo é de 10 a 19 anos na atividade leiteira. Assim, a maior parte dos entrevistados do cluster de alta produtividade entrou na atividade recentemente, não tendo passado por questões institucionais, organizacionais e competitivas muito diversas das presentes atualmente, como regulamentação do mercado, políticas protecionistas, padrões de qualidade menos rigorosos e produção unicamente voltada para o mercado interno. ${ }^{8}$

\footnotetext{
Ressalta-se que a Instrução Normativa n.51, de 2002, importante divisor de águas na produção leiteira, entrou em vigor no Paraná em 2006.
} 
Tabela 11 - Tempo na atividade leiteira (anos)

\begin{tabular}{lcc|cc|cc}
\hline & \multicolumn{2}{c}{ Média } & \multicolumn{2}{c}{ Alta } & \multicolumn{2}{c}{ Baixa } \\
\cline { 2 - 7 } Média (anos) & $\mathbf{N}$ & Média & $\mathbf{N}$ & Média & N & Média \\
\hline \multicolumn{1}{c}{ Estratificação } & $\mathbf{N}$ & 10,1 & 26 & 7,3 & 86 & 8,8 \\
\hline 0 a 4 anos & 17 & 19 & 11 & 42 & 20 & 23 \\
5 a 9 anos & 25 & 28 & 6 & 23 & 29 & 34 \\
10 a 19 anos & 37 & 41 & 8 & 31 & 32 & 37 \\
20 anos ou mais & 11 & 12 & 1 & 4 & 5 & 6 \\
\hline
\end{tabular}

Fonte: Dados da pesquisa.

Pela Tabela 12, observa-se, para os três grupos, o rendimento mensal como principal incentivador para atuação na produção leiteira pelos produtores entrevistados. Tal fato está associado à possibilidade de manter fluxo de entrada de recursos para sobrevivência e capital de giro para condução das atividades agropecuárias. Destaca-se, entretanto, que $15 \%$ dos produtores do cluster de baixa produtividade indicaram limitações da terra (de tamanho, de relevo, edáficos) como um entrave para condução de outras atividades agropecuárias. Esses produtores são direcionados à bovinocultura de leite em decorrência de uma especificidade do ativo "terra", dado que determinadas atividades somente se tornam financeiramente viáveis em grandes áreas, com solo apropriado e em relevo não acidentado, por exemplo. Além de limitar as opções para o produtor, a mencionada especificidade da terra também pode representar um fator negativo na própria atividade leiteira, pois restrições de área e piores condições de solo e de relevo podem comprometer o desempenho da produção. 
Tabela 12 - Principal motivo por atuar na produção leiteira

\begin{tabular}{l|c|c|c|c|c|c}
\hline \multirow{2}{*}{ Motivo } & \multicolumn{2}{|c|}{ Média } & \multicolumn{2}{c|}{ Alta } & \multicolumn{2}{c}{ Baixa } \\
\cline { 2 - 7 } & $\mathbf{N}$ & $\%$ & N & $\%$ & N & $\%$ \\
\hline Renda mensal & 79 & $88 \%$ & 25 & $96 \%$ & 71 & $83 \%$ \\
Mercado certo & 4 & $4 \%$ & 0 & $0 \%$ & 1 & $1 \%$ \\
Maior conhecimento & 3 & $3 \%$ & 1 & $4 \%$ & 1 & $1 \%$ \\
Incentivos governamentais & 0 & $0 \%$ & 0 & $0 \%$ & 0 & $0 \%$ \\
Terra imprópria para agricultura & 4 & $4 \%$ & 0 & $0 \%$ & 13 & $15 \%$ \\
\hline Total & $\mathbf{9 0}$ & $\mathbf{1 0 0} \%$ & $\mathbf{2 6}$ & $\mathbf{1 0 0} \%$ & $\mathbf{8 6}$ & $\mathbf{1 0 0 \%}$ \\
\hline
\end{tabular}

Fonte: Dados da pesquisa.

Alguns aspectos tecnológicos da atividade leiteira na região também foram tratados na pesquisa. O uso de técnicas e tecnologias específicas para a atividade leiteira é relativamente disseminado nos três clusters, sendo disseminado em mais da metade dos produtores entrevistados (Tabela 13). Maior percentual de produtores do cluster de alta produtividade declarou usar cada uma das técnicas e tecnologias apontadas, enquanto os de baixa produtividade apresentam os percentuais mais baixos. Maiores níveis de produtividade no Paraná estão associados a níveis tecnológicos mais elevados. Nesse sentido, o uso de suplementação alimentar (silagem e/ou ração) e de rebanho especializado, por exemplo, é importante fator para aumento da produtividade, conforme já indicado em IPARDES (2008). Assim, os baixos índices de produtividade podem estar associados a menores níveis tecnológicos dos produtores entrevistados. 
Tabela 13 - Técnicas e tecnologias para a atividade leiteira

\begin{tabular}{llccccc}
\hline & \multicolumn{2}{c}{ Média } & \multicolumn{2}{c}{ Alta } & \multicolumn{2}{c}{ Baixa } \\
& $\mathbf{N}$ & $\mathbf{\%}$ & $\mathbf{N}$ & $\mathbf{\%}$ & $\mathbf{N}$ & \% \\
\hline Rebanho especializado* & 63 & 70 & 19 & 73 & 56 & 65 \\
Tanque de expansão & 66 & 73 & 24 & 92 & 58 & 67 \\
Ordenhadeira mecânica & 84 & 93 & 24 & 92 & 77 & 90 \\
Suplementação alimentar & 67 & 74 & 20 & 77 & 57 & 66 \\
Pastejo rotacionado & 69 & 77 & 19 & 73 & 61 & 71 \\
Inseminação artificial & 48 & 53 & 15 & 58 & 45 & 52 \\
\hline
\end{tabular}

* Raças Jersey e/ou Holandês.

Fonte: Dados da pesquisa.

Outra variável tecnológica relevante na atividade leiteira é o percentual de vacas em lactação. A recomendação técnica é que $83 \%$ das vacas sejam mantidas em lactação, a fim de otimizar o retorno econômico da atividade. O percentual médio de vacas em lactação para produtores do estado do Paraná é de 60,3\% (IPARDES, 2008). Conforme dados da Tabela 14, os produtores entrevistados apresentam proporção bem acima da média estadual para os três grupos. Entretanto, apenas o cluster de produtores com alta produtividade apresentou percentual médio próximo ao recomendado ( $82,4 \%$ de vacas em lactação), sendo o cluster de baixa produtividade o que apresentou o menor valor médio. Nesse caso, além de apresentarem maior volume de leite por vaca em lactação, os produtores com nível de produtividade elevada ainda possuem maior proporção do rebanho em produção, o que incrementa o seu desempenho na atividade.

Tabela 14 - Percentual de vacas em lactação

\begin{tabular}{lccc}
\hline \multicolumn{1}{c}{ Vacas em lactação (\%) } & Média & Alta & Baixa \\
\hline Média & 74,0 & 82,4 & 71,7 \\
Desvio padrão & 11,6 & 9,4 & 15,8 \\
\hline
\end{tabular}

Fonte: Dados da pesquisa. 
Níveis técnicos e tecnológicos para a gestão agropecuária foram averiguados junto aos entrevistados ao se investigar o uso de ferramentas e procedimentos gerenciais. Enquanto 35\% dos produtores do cluster de alta produtividade afirmaram fazer uso de sistemas de gestão, para os clusters de média e baixa produtividades, essas proporções foram, respectivamente, de $29 \%$ e $27 \%$ (Tabela 15). Além disso, enquanto apenas $3 \%$ e $6 \%$ dos produtores de média e baixa produtividades, respectivamente, planejam os custos de produção, esse percentual é de $19 \%$ para o cluster de alta produtividade. Observa-se, portanto, uma relação direta entre os níveis de produtividade e o uso de ferramentas e práticas de gestão, indicando que estas podem auxiliar o produtor na tomada de decisão, direcionando as ações em busca de melhor desempenho.

Tabela 15 - Uso de ferramentas e procedimentos de gestão da atividade leiteira

\begin{tabular}{l|c|c|c|c|c|c}
\hline \multirow{2}{*}{} & \multicolumn{2}{|c|}{ Média } & \multicolumn{2}{c|}{ Alta } & \multicolumn{2}{c}{ Baixa } \\
\cline { 2 - 7 } & $\mathbf{N}$ & $\%$ & $\mathbf{N}$ & $\%$ & $\mathbf{N}$ & $\%$ \\
\hline Sistemas de gestão & 26 & $29 \%$ & 9 & $35 \%$ & 23 & $27 \%$ \\
\hline Planejamento de custos & 5 & $6 \%$ & 5 & $19 \%$ & 3 & $3 \%$ \\
\hline
\end{tabular}

Fonte: Dados da pesquisa.

Outro fator relevante para o desempenho na atividade é o acesso à capacitação e assistência técnica. Observa-se, pela Tabela 16, considerável acesso à assistência técnica pelos produtores de todos os clusters: $69 \%$ dos produtores do grupo de baixa produtividade; $92 \%$ do cluster de média produtividade; e $92 \%$ do cluster de alta produtividade tiveram acesso à assistência técnica, proporção bem acima da média paranaense, de 53,8\% (IPARDES, 2008). Entre os entrevistados, os produtores com baixos níveis de produtividade apresentaram menor acesso à assistência técnica, o que pode comprometer o desempenho na atividade. Considerando a principal fonte de assistência técnica, destaca-se o papel das cooperativas e associações e de empresas privadas. 
É necessário enfatizar que grande parte de tais fontes corresponde a processadoras que adquirem o leite dos produtores, sendo este um papel assumido por esse segmento no SAG em estudo. Ademais, os dados da Tabela 16 indicam que fontes de assistência técnica oficial, tais como o EMATER, são pouco utilizadas pelos produtores entrevistados, e as universidades, por sua vez, não foram citadas por nenhum entrevistado como fonte de assistência técnica para a atividade leiteira. Tais constatações podem indicar, por um lado, uma carência de atuação de organismos oficiais de assistência técnica na região e, por outro lado, limitações de acesso à informação pelos produtores, que ficam restritos às orientações fornecidas por seus compradores.

Tabela 16 - Principal fonte de assistência técnica

\begin{tabular}{l|c|c|c|c|c|c}
\hline \multirow{2}{*}{ Fonte } & \multicolumn{2}{|c|}{ Média } & \multicolumn{2}{c|}{ Alta } & \multicolumn{2}{c}{ Baixa } \\
\cline { 2 - 8 } & $\mathbf{N}$ & $\mathbf{\%}$ & $\mathbf{N}$ & $\mathbf{\%}$ & $\mathbf{N}$ & $\%$ \\
\hline Não tiveram assistência técnica & $\mathbf{7}$ & $\mathbf{8 \%}$ & $\mathbf{2}$ & $\mathbf{8 \%}$ & $\mathbf{2 7}$ & $\mathbf{3 1 \%}$ \\
\hline Assistência técnica oficial & 5 & $6 \%$ & 2 & $8 \%$ & 8 & $14 \%$ \\
Associação / cooperativa & 37 & $45 \%$ & 10 & $42 \%$ & 26 & $44 \%$ \\
Profissionais independentes & 15 & $18 \%$ & 3 & $13 \%$ & 4 & $7 \%$ \\
Empresa privada & 19 & $23 \%$ & 7 & $29 \%$ & 17 & $29 \%$ \\
Outros & 7 & $8 \%$ & 2 & $8 \%$ & 4 & $7 \%$ \\
\hline Total & $\mathbf{8 3}$ & $\mathbf{1 0 0} \%$ & $\mathbf{2 4}$ & $\mathbf{1 0 0} \%$ & $\mathbf{5 9}$ & $\mathbf{1 0 0 \%}$ \\
\hline
\end{tabular}

Fonte: Dados da pesquisa.

A participação em formas associativas pode se tornar fator relevante para o desempenho na atividade, dado que viabiliza a troca de informações, ganhos de conhecimento e economias de escala e escopo nas fases de produção, transformação e comercialização do leite. Os dados da Tabela 17 indicam que a maior parte dos produtores, dos três clusters, comercializa o leite com processadoras cooperativas, enfatizando o perfil cooperativista da região (IPARDES, 2008; 2009). Pelo estudo, este fator não se mostrou determinante nas diferenças entre os grupos, dada a semelhança entre eles neste aspecto. 
Pela Tabela 17, observa-se também que poucos produtores declararam fazer parte do mercado informal, realizando venda direta ao varejo e/ou a consumidores finais. Tais produtores estão nos grupos de média e baixa produtividade, podendo ter relação com dificuldades de acesso ao mercado formal por questões de volume produzido ou níveis tecnológicos mais baixos (ausência de tanque de expansão, por exemplo).

Tabela 17 - Principal agente comprador

\begin{tabular}{l|cc|c|c|cc}
\hline \multirow{2}{*}{ Agente comprador } & \multicolumn{2}{|c|}{ Média } & \multicolumn{2}{c|}{ Alta } & \multicolumn{2}{c}{ Baixa } \\
\cline { 2 - 8 } & $\mathbf{N}$ & $\mathbf{\%}$ & $\mathbf{N}$ & $\mathbf{\%}$ & $\mathbf{N}$ & $\%$ \\
\hline Empresa cooperativa & 77 & $86 \%$ & 24 & $92 \%$ & 73 & $85 \%$ \\
Empresa não cooperativa & 12 & $13 \%$ & 2 & $8 \%$ & 10 & $12 \%$ \\
Venda direta & 1 & $1 \%$ & 0 & $0 \%$ & 3 & $3 \%$ \\
\hline Total & $\mathbf{9 0}$ & $\mathbf{1 0 0} \%$ & $\mathbf{2 6}$ & $\mathbf{1 0 0} \%$ & $\mathbf{8 6}$ & $\mathbf{1 0 0} \%$ \\
\hline
\end{tabular}

Fonte: Dados da pesquisa, 2010.

Os dados da Tabela 18 indicam que os produtores de leite, em sua maioria, são tomadores de preço, com predominância de definição pelo agente comprador para os três grupos em análise. Para 19\% dos produtores do cluster de alta produtividade, entretanto, os preços não são definidos pelo agente comprador ou correspondentes ao preço de mercado. Eles apontaram outras formas de definição do preço tais como negociações diretas com o comprador ou formação de grupos para definição de preços. Assim, tais produtores podem alcançar melhor remuneração, o que se reverte em melhor desempenho na atividade. 
Tabela 18 - Definição do preço pago pelo leite

\begin{tabular}{l|cc|c|c|cc}
\hline \multirow{2}{*}{ Definição } & \multicolumn{2}{|c|}{ Média } & \multicolumn{2}{c|}{ Alta } & \multicolumn{2}{c}{ Baixa } \\
\cline { 2 - 8 } & $\mathbf{N}$ & $\%$ & N & $\%$ & N & $\%$ \\
\hline Preço de mercado & 11 & $12 \%$ & 1 & $4 \%$ & 12 & $14 \%$ \\
Agente comprador & 69 & $77 \%$ & 20 & $77 \%$ & 69 & $80 \%$ \\
Outros & 10 & $11 \%$ & 5 & $19 \%$ & 5 & $6 \%$ \\
\hline Total & $\mathbf{9 0}$ & $\mathbf{1 0 0} \%$ & $\mathbf{2 6}$ & $\mathbf{1 0 0} \%$ & $\mathbf{8 6}$ & $\mathbf{1 0 0} \%$ \\
\hline
\end{tabular}

Fonte: Dados da pesquisa.

Ao discorrerem sobre os principais fatores que contribuíram para o aumento da produtividade, os produtores, nos três clusters, destacaram primeiramente o melhoramento genético, em consonância com a importância de um rebanho leiteiro especializado para alcance de melhor desempenho (Tabela 19). De fato, produtores no Paraná com maior proporção de raças leiteiras apresentam maiores níveis de produtividade (IPARDES, 2008).

Diferenças entre os três clusters podem ser apontadas: os produtores com elevados níveis de produtividade apontaram a especialização da mão de obra como fator relevante para melhoria, o que condiz com a maior frequência de produtores nesse grupo de capacitação da mão de obra. A especialização em tecnologia foi destacada por $31 \%$ dos produtores do cluster de baixa produtividade, sendo apontada por $17 \%$ no grupo de média produtividade e por $8 \%$ dos produtores do cluster de alta produtividade (Tabela 19). À medida que produtores com níveis mais elevados de produtividade já se encontram tecnificados, pois fizeram tais investimentos anteriormente, este fator passa a não se mostrar relevante para alcances mais recentes de melhorias. Assim, os pecuaristas mais produtivos parecem já ter passado pela fase de incremento tecnológico, estando recentemente preocupados com adequação da mão de obra e especialização do rebanho.

Ademais, ressalta-se que, considerando o menor tempo na atividade declarado pelos produtores de alta produtividade, estes podem ter adotado 
soluções técnicas de última geração - mais eficientes e apropriadas. Os produtores há longo tempo na atividade, em contraposição, podem não ter acompanhado a evolução da trajetória tecnológica no setor, perpetuando uma tecnologia e/ou sistema produtivo menos eficiente.

Tabela 19 - Fatores que contribuíram para a melhoria da produtividade na atividade leiteira*

\begin{tabular}{lcccccc}
\hline \multirow{2}{*}{ Fatores } & \multicolumn{2}{c}{ Média } & \multicolumn{2}{c}{ Alta } & \multicolumn{2}{c}{ Baixa } \\
& $\mathbf{N}$ & $\mathbf{\%}$ & $\mathbf{N}$ & $\mathbf{\%}$ & $\mathbf{N}$ & $\mathbf{\%}$ \\
\hline Especialização mão-de-obra & 9 & 10 & 9 & 35 & 26 & 30 \\
Especialização em tecnologia & 15 & 17 & 2 & 8 & 27 & 31 \\
Melhoramento genético & 27 & 30 & 11 & 42 & 49 & 57 \\
Assistência técnica & 18 & 20 & 5 & 19 & 25 & 29 \\
\hline
\end{tabular}

* Respostas múltiplas

Fonte: Dados da pesquisa.

\section{Conclusões}

Recentes alterações institucionais, organizacionais e tecnológicas têm influenciado a dinâmica e o desempenho dos agentes no SAG do leite. O trabalho buscou identificar aspectos socioeconômicos, produtivos e tecnológicos que diferenciam produtores de leite da região Sudoeste do Paraná, segundo diferentes níveis de produtividade.

Em termos gerais, foram encontradas algumas diferenças entre os clusters estudados, o que indica que maiores níveis de produtividade podem estar associados a alguns fatores, tais como nível tecnológico, uso de mecanismos de gestão, tempo na atividade leiteira, tamanho de área e acesso a recursos, capacitação e assistência técnica, entre outros.

Possíveis propostas para a melhoria de desempenho dos produtores de leite na região podem estar associadas à intensificação e divulgação de programas de assistência e capacitação técnica e gerencial de produtores, 
ao incentivo ao acesso a crédito para investimento e melhoria da atividade leiteira (principalmente tendo em vista a necessidade de incremento tecnológico frente às novas exigências da IN 51$)^{9}$ e à organização em formas associativas de coordenação horizontal para troca de conhecimento e ganhos de escala e escopo, condição especialmente importante para pequenos produtores.

\section{Referências}

BANKUTI, S. M. S Análise das transações e estruturas de governança na cadeia produtiva do leite: a França como referência. Tese (Tese de Doutorado apresentada ao Programa Engenharia de Produção da Universidade Federal de São Carlos), São Carlos, 2007.

BRASIL. Lei 4504/64, de 30 de novembro de 1964. Dispõe sobre o Estatuto da Terra e dá outras providências. Diário Oficial da União, Brasília - DF, 30 nov. 1964. Suplemento.

. Instrução Normativa n. 32, de 30 de junho de 2011. Ministério da Agricultura, Pecuária e Abastecimento, 2001. Diário Oficial da União, Brasília- DF. Disponível em <www.agricultura.gov.br>. Acesso em 18 out. 2011.

DURAN, B. S. ODELL, P. L. Cluster analysis: a survey. Berlin, Spring-Verlag, 1974.

DÜRR, J. W. Programa nacional de melhoria da qualidade do leite: uma oportunidade única. In: DÜRR, J. W.; CARVALHO, M. P. de; SANTOS, M. V. (Orgs.). O compromisso com a qualidade do leite no Brasil. 1. ed. Passo Fundo: UPF, 2004. p. 38-56.

9 Segundo a IN 32/ 2011, as novas exigências da IN 51 passarão a vigorar nos Estados do Sul, Sudeste e CentroOeste a partir de janeiro de 2012. (BRASIL, 2011). 
IBGE. Instituto Brasileiro de Geografia e Estatística. Pesquisa da Pecuária Municipal (2009). Disponível em: <www.ibge.gov.br $>$. Acesso em: 10 jul. 2010.

IPARDES. Instituto Paranaense de Desenvolvimento Econômico e Social. Caracterização socioeconômica da atividade leiteira no Paraná. Curitiba, Ipardes: 2008.

. Caracterização da indústria de processamento e transformação do leite no Paraná. Curitiba: Ipardes, 2010. Ipardes: 2009.

Sudoeste Paranaense: especificidades e diversidades. Curitiba, KAUFMAN, L.; ROUSSEAU, W. Finding groups in data: an introduction to cluster analysis. New York: John Wiley \& Son, 1990.

JANK, M. S. FARINA, E. GALAN, V. B. Competitividade do Sistema Agroindustrial do Leite. PENSA-USP: São Paulo- SP, 1999.

LEBART, L.; MORINEAU, A. FÉNELON, J. P. Traitment de Données Statistiques - Méthodes et Programmes. 2ème éd., Paris: Dunod, 2006.

MARTINS, P. C. A importância da qualidade do leite. In: CARVALHO, M. P.; SANTOS, M. V. Estratégia e competitividade na cadeia de produção do leite. Passo Fundo: Gráfica Editora Berthier, 2005. p. 47 $-53$.

PARRÉ, J. L.; SANTOS, G. T. dos; MASSUDA, E. M.; ALVES, A. F. Análise espacial da produção e produtividade da pecuária leiteira paranaense. In: SANTOS, G T; MASSUDA, E M; KAZAMA, D C S; JOBIM, C C; BRANCO, A F. (Org.). Bovinocultura leiteira: bases zootécnicas, fisiológicas e de produção. 1 ed. Maringá, 2010, v. 1, p. 29 46. 
TETZNER, T. A. D.; BENEDETTI, E.; GUIMARÃES, E. C.; PERES, R.F.G. Prevalência de resíduos de antibióticos em amostras de leite cru na região do Triângulo Mineiro, MG. Revista Higiene Alimentar. São Paulo, v. 19, n. 130, p. $69-72$, abr. 2005.

ZANMARIA, N. Inserção dos produtores na cadeia do leite e seu nível de produtividade: um estudo para a região sudoeste do Paraná. Dissertação (Dissertação de Mestrado apresentada ao Programa de Pós-graduação em Ciências Econômicas da Universidade Estadual de Maringá), Maringá, 2010. 
REVISTA DE ECONOMIA E AGRONEGÓCIO, VOL.9, No 2 